\title{
SCIENCE IN THE U.S.S.R.*
}

\section{EVOLUTIONARY BIOLOGY AND RELATED SUBJECTS}

\section{BY DR. JULIAN HUXLEY, F.R.S.}

$I^{\mathrm{N}}$ the U.S.S.R., a convergent attack on the evolution problem is being made from many angles simultaneously - from that of geneties, of taxonomy, of ecology, of cytology, of field studies and behaviour, of mathematical analysis, of comparative anatomy, of palæontology. In this, the U.S.S.R. resembles Britain, the United States and other countries, though it is interesting to find that during the War a good deal of the work has been earried on independently, in total or partial ignorance of research elsewhere. The approach has in general been along the same neo-Darwinian lines, involving acceptance of neo-Mendelism, as in Britain and the United States, though perhaps with even greater emphasis on strict selectionist prineiples. This is all the more interesting, since in the U.S.S.R. neo-Darwinism is in sharp contrast with the revolutionary views of the botanist and agriculturist Lysenko. Lysenko's conclusions and theories demand an article to themselves. Here we can only say that though Lysenko claims to be a true Darwinian, his contentions involve a sweoping form of Lamarckian inheritance, as well as remarkable effects of scion on stock in grafting, and their hereditary transmission. Further, he expressly states his disbelief in Mendelism or any other particulate principle of heredity. Lysenko is in a powerful position, both scientifically, as president of the Lenin All Union Academy of Agricultural Sciences, and politically, as vice-chairman of the Supreme Soviet. However, in spite of this, the neo-Mendelian and neoDarwinian selectionists continue to turn out large quantities of excellent work (thus disproving the contention sometimes advanced by non-Russian men of science, that scientific theory in the U.S.S.R. is always subject to political considerations). Indeed, in Lysenko's own Institute are to be found research workers on Drosophila genetics and cytology, and a former member of the staff of Vavilov, the eminent plant geneticist (now dead), who was Lysenko's most prominent antagonist before the War.

In what follows, I propose to mention some of the work in the more important fields of research which I came across during our two weeks in the U.S.S.R., in the hope that this will facilitate that renewal of contacts which is so desirable after the isolation caused by the War.

Work on Drosophila is in progress in numerous institutions. In Dubinin's Laboratory of Genetics in the Institute of Cytology (Moscow), Dubinin himself is studying the selective effects of various inversions in natural populations. One inversion has a selective advantage over the normal at low temperatures. Several others are at a disadvantage at low temperatures, and are mueh more numerous in urban conditions: the result is to produce a balanced polymorphism as between urban and rural populations, similar to that found with industrial melanism in moths, though the selective agencies are quite different. Berg and Dubinin have also found a seasonal balance as regards the mutant wing-vein character extra-analis. All the polygenes responsible for this character are in one chromosome, a state of affairs which Dubinin maintains must be due to

* Continued frcm p. 228. selection. Dubinin has also some very interesting work on mutation-rate-its general control by selection; the existence of strains highly mutable for yellow; etc.

In conversation, Dubinin recalled the fact that in 1931 he (with Romashov), had, simultaneously with Sewall Wright but quite independently, enunciated the prineiple of non-adaptive evolution in small populations. (Unfortunately, he used the cumbersome phrase 'genetical-automatic processes', and the convenient American term 'drift' has quite superseded this.) Siderov is studying the position-effect with regard to yellow. The frequency of yellow mosaics is related to contiguity of the yellow locus to the 'inert' region of the chromosome; it is also related to development-thus the manifestation of yellowmosaicism is less frequent on the head than on the body. Other problems of physiological genetics will be investigated by Rappaport on his return from service.

Work on mutation is also being carried on by Shapiro in Academician Serebrovsky's Department of Genetics in the University of Moscow (though mainly on a new genetic object, the melichid fly Dermemetopa); by Olenov in the Genetics Department of the Roentgen Institute in Leningrad; and by Miss Berg in Schmalhausen's laboratory in Moscow. Berg is also doing interesting work on natural populations, especially on the evolution of dominance, and on the effects on different mutants of the varying types and intensities of selection which prevail at different periods of the annual cycle.

In Academician Lysenko's Institute of Genetics, apart from Lysenko's own work (with Glushehenko and others) on grafting and the inheritance of its effects, which I do not propose to discuss here, Prokofieva is making an extremely interesting study, from the cytological aspect, of the metabolic cycle of ehromosomes (which she has christened 'heteroeyclicity'), notably in regard to the difference between the paternal and maternal genomes. Nujdin is working on Drosophila here, and on his return from military service, Belgovsky will continue his work on the pure genetics of Drosophila.

In mathematical geneties and evolution theory, important work is being done by Kolmogorov, Malinovski, Smimov, Ignatiev, Romashov, Schmalhausen and others. Schmalhausen is working on what he calls 'stabilizing selection' and the different reaction-norms to be expected in different types of environment.

It was of great interest to find that the Pavlov Institute at Koltushi (Leningrad) has a department devoted to the genetics of behaviour. Here, Dr. Masing is studying the inheritance of phototaxis in Drosophila, and has also obtained valuable results on the genetic basis of egg-laying preferences, which help to explain the origin of 'biological races' and monophagous species. Meanwhile, Promptov is studying the effects of environment and of heredity on activity and other aspects of behaviour in finches. This, I believe, is the only work that has been done on the genetics of behaviour in wild bird species. The study of the inheritance of temperamental types in dogs, begun under Pavlov, will be continued, and is to be extended by similar work on pure breeds, the material so far having been genetically quite heterogeneous.

In the Institute of Cytology, Sacharov, using colchicine, has produced a valuable new tetraploid 


\section{No. 3957 September I, $1945 \quad$ N A T U R E}

form of buckwheat. He has also found that in an artificial poppy tetraploid, the tapetal cells of the anthers remain octoploid, as in the normal diploidan interesting example of regulation. Frolova, as well as studying the cytology of these tetraploids, is doing work on the digestion of different parts of chromosomes by different enzymes and other agencies, which should be of general importance. Peshkov has obtained what appears to be conclusive evidence of chromosomes and their division in a bacterium (a giant form, Karyophanon), and is also studying the peculiar endomitosis of Chara. In Navashin's laboratory in the same Institute, a giant and highly focund tetraploid of a valuable rubber-producing composite has been artificially produced. Navashin himself is now studying the dynamics of mitosis in Crepis.

In the Institute's Laboratory of Experimental Embryology (besides interesting work on morphogenesis which cannot be discussed here) Astaurov, working on silkworms, has obtained both parthenogenetic males and females. Schmidt is continuing his well-known researches on the nemertine Lineus, which showed the existence of two modes of development, one where the eggs are larger and all develop, producing Desor larvæ and green adults, and the other where the majority degenerate after early segmentation, and are ingested by the remainder, which develop into large-mouthed larvæ and red adults. He now considers these as separate but close species, differentiated after genetic isolation. In the red species ( $L$. ruber), he now finds that the percentage of degenerating eggs is the same (87 per cent) in two widely separated subspecies with slightly different-sized eggs and markedly different eggtotals. He suggests that this depends on a genetic mechanism involving balanced lethals-if so, a remarkable case of lethals being utilized to produce an adaptive result.

'Close species' in plants and other botanical speciesproblems are being studied by Rosanova in the University Genetics Laboratory. Here also, Khostova has been independently repeating some of Lysenko's work on the effects of grafting on tomatoes, I understand with largely negative results; Alikhanyan is studying structural mutations; and the director, Serebrovsky, has been working on the genetics of parasitoids for practical purposes. Among other results he has obtained a wingless strain of Sitotroga to serve as food (host) for the useful Trichogramma; this is of importance as reducing the danger of spread of Sitotroga, which is a pest.

In Schmalhausen's laboratory, Mashkovtsev and his colleagues are doing a good deal to generalize the modern thesis that courtship and display (and other external stimuli connected with the breeding habitat) have a physiological effect in ripening the female gonads in birds and mammals.

Very interesting work is being done by C. F. Gause. Employing ciliates, he has given the first experimental proof of the efficacy of organic selection. $\mathrm{He}$ finds that both salinity and temperature changes normally induce modifications in body-size; when conjugation is induced, segregants appear with a large range of body-size, but only those survive which are of the same type as the modifications. Gause is now devoting himself mainly to medical research on gramicidin, but hopes to give some of his time to evolutionary studies.

Alpatov has shown that the correlation which he had previously established between tongue-length and latitude in bees is found only in the workers, not in queens or drones, and is thus presumably an adaptation to the flowers visited. He proposes to extend this work to bumblebees. He has also established the important fact that the irreversibility of the transformation of the head-louse to the body-louse is a selection effect. The head-louse shows a great range of variability; in the five or six generations required to transform it into the body-louse, heavy mortality occurs and the variability is reduced, so that the reverse process is impossible. The bodylouse is thus a specialized type, produced by a selection which Alpatov considers is mainly one for tolerance of lower temperature.

Work on the genetics of cancer is being done in the Genetics Department of the Oncological Institute in Moscow under Martinova, and on the genetics of coarse fish by Romashov in the Genetics Department of the Freshwater (Pond) Fish Institution in Moseow. I was informed that information on the genetics of fur-bearing animals and on their variation and polymorphism in Nature was to be obtained from the Central Fur Laboratory of the People's Commissariat for Foreign Trade (Profs. Petrayev and Manteufel), but was unable to make eontact with them.

In taxonomy, excellent work is being done, both in the University Museum of Zoology, Moscow, and in the large Museum of Zoology in Leningrad (famous for its specimens of mammoth and woolly rhinoceros with skin and hair), to which is attached the Zoological Institute of the Academy.

In Moscow, Dementiev told me that he had been so stimulated by the publication of the "Handbook of British Birds" during the War, that he and a team of collaborators are now preparing a handbook of the birds of the U.S.S.R., which will aim at very full ecological treatment. This will be a formidable task, as there are 675 species to cover; but it will be of the greatest value to ornithology and to taxonomy in general. Heptner, the mammalogist here, is pursuing zoogeographical studies, as is Turov. Heptner is also working on polymorphism in Mustela, Myospalax, Arvicola, etc. The marten (Martes martes) and the sable (M. zibellinus) show a 'hybrid zone' very similar to that between the carrion and hoodie crows. There is also a chair of zoogeography in the University of Moscow, held by Bobrinskoi, who has just published a book on the mammals of the U.S.S.R., while Puzanov of the University of Gorki has published a text-book of zoogeography. Lukin, professor of biology at the University of Kharkov, is also working on biogeography and has published a book on Darwinism and the geographical variation of organisms.

In Leningrad, much work is being done on the taxonomy of the various main groups of animals, and numerous books are being published, including many volumes of the detailed Fauna of the U.S.S.R. (chiefly anatomical and systematic). At the Leningrad Museum an interesting feature (unfortunately rare in Britain) was the linking of museum systematics with physiology and ecology. Thus the entomologist Kushentsov is writing a book on the comparative physiology of insects, and Rubtzov works chiefly on the ecology of Diptera. The curator of mammals, Vinogradov, is also professor of vertebrate systematics and ecology in the University of Leningrad, and maintains a field station for his students. In the University Department of Entomology, Shvanvich has perfected a new method for demonstrating the true value of 'ruptive' coloration in Lepidoptera, in breaking up the flat plane of the wings into a number of apparently different levels : in some cases the result simulates a 
foreground of grass stems against a dark background. $\mathrm{H}_{e}$ has also made a valuable study of the evolution of wing pattern within single families-a veritable comparative anatomy of pattern and its elements.

To return to ecology, the leading animal ecologist in the U.S.S.R. is Formosov. Unfortunately, he and his staff were away in the field at the time of our visit, so that I had no opportunity of hearing of their current researches, nor did I make contact with Sinskaya or other plant ecologists. Attached to the Zoological Gardens in Moscow is a small but interesting institute, the Laboratory of Experimental Ecology, under Kalabukhov. $\mathrm{He}_{\theta}$ and his assistant Afonska are making quantitative studies of the activity, temperature preferences, respiration, and oxygen consumption of various mammals-bears, foxes, field mice, hamsters, martens, etc.- and finding adaptive correlations with local environmental conditions. Work is also being done on the change of colour to winter white in Cricetulus and Lepus.

At the Museum Darwinianum in Moscow, in addition to the remarkable exhibition methods (which include a large number of striking paintings and sculptures by the artist Vatagin), Kohts, the director, has an extraordinary collection of aberrations in various species of birds and mammals. The most interesting are in blackcock, where more than 200 million specimens from the markets for some four hundred years had been gone through! As a result, Kohts is able to say that a dilute ("blue') form oceurs once in about $2 \frac{1}{2}$ million specimens, a form with checked black-and-white belly once in 10 million, and so on. Mme. Kohts is continuing her work on the behaviour of chimpanzees (a subject which is also being studied, with interesting results, at the Pavlov Institute at Koltushi).

Boris Zavadovsky also has a Museum of Evolution in Moscow, but this is more popular and takes in more general biology. It comprises a number of living exhibits. Zavadovsky writes a good deal on theoretical biology and on Marxism in biology, as well as doing practical work on artificial insemination, on pregnancy tests, and tests for the sex of unborn mammalian offspring.

In general, much less research is being carried on in university departments than in the special institutes of the Academy of Sciences and other nonuniversity institutions. However, the disparity does not seem to be so great in biology as in the physical sciences. Genetics is at present taught only in the University of Moscow : specially able students from other universities may be sent to Moscow to take this course. Genetics is studied during the last two and a half years of the five-year undergraduate course in biology; there are now about twenty genetics specialists. During their final year, students are encouraged to do small pieces of research under guidance. The courses in plant and animal genetics are different, but all genetics students do some work with Drosophila, as well as cytology, biometry and phenogenetics.

As we only had a short time in the U.S.S.R. and did not visit many cities, the above account of work in progress is very incomplete (though it appears that a large percentage of the more important research is concentrated in Moscow and Leningrad). Thus I was unable to see anything of the work in agricultural genetics, notably the genetical research being carried on in the huge agricultural institution, the Timiriazev Academy near Moscow (where I understand much valuable work on polyploidy and on the genetics of cereals is in progress under Academician Jebrak); nor could I see that in the equally huge Forestry Research Institute near Leningrad, or the work on polyploidy in Breslavetz's department at the Botanical Garden of the University of Moseow. Karpechenko, the well-known plant geneticist, is unfortunately missing, presumed dead.

I had not the time to discover what had happened to the remarkable programme of work on the evolution and genetics of crop plants initiated by Vavilov (except that some of the seed-collections left at Leningrad were eaten during the siege). The abundant and valuable work in palæontology is being described by Prof. D. M. S. Watson and Dr. Edwards. Here I will only record the excitement of seeing a fossil Paleoniscid fish larva from the Jurassic, with eyes and yolk-sac beautifully preserved.

In general, I may sum upmy impressions as follows. In spite of the insistence during the last four years that Russian biologists, like other men of science in the U.S.S.R., should do some work of importance for the war effort, pure research seems to have been kept going to a somewhat greater extent than in Britain during the War (and, according to some of the American delegation, than in the United States.)

In some branches of Russian science, a certain spirit of scientific nationalism is to be observed. There is little of this, however, in general biology, apart from the efforts made in certain quarters to elevate Michurin from the position of an agricultural and horticultural empiricist to that of a great scientific pioneer and discoverer (there is even a town which has been re-christened Michurinsk, where much of Lysenko's work is now being carried on).

If in the U.S.S.R. no outstanding discoveries appear to have been made, no new principles established, in the field of general biology during the last few years (again I defer any discussion of Lysenko's work until later), yet the work has been of high quality, many-sided in its approach, and of great volume (though not so voluminous as, for example, in geology or agriculture).

In spite of the War, my Russian colleagues seem to have managed to obtain rather more knowledge of British and American results than we did of their work, though their supply of foreign and scientific books and especially journals is still very inadequate. They all showed the greatest courtesy and friendliness and were anxious to tell us of all they had been doing and thinking. They are hoping for a rapid improvement in the facilities for interchange of personnel, as well as of reprints, journals and books.

The U.S.S.R. is taking its place as one of the foremost countries in biological research, and I anticipate that they will soon be leading the world in some fields, notably in the relation between ecology, field study, taxonomy, genetics and evolution, where their vast continuous territory, with its extremes of environmental conditions, provides them with unrivalled opportunities.

\section{CRYSTALLOGRAPHY By DR. W. A. WOOSTER}

Department of Mineralogy and Petrology, Cambridge

NE of the evil effects of the War has been the virtual isolation of scientific workers from their colleagues in foreign countries, and it was a particularly welcome invitation which the Russian Government extended to British crystallographers. During the War the laboratories in Moscow and Leningrad 